\title{
KEPATUHAN REMAJA SMA NEGERI DI KOTA DENPASAR TERHADAP KESELAMATAN BERKENDARA (SAFETY RIDING) SEPEDA MOTOR
}

\author{
Egiya Goldarosa Sinuraya*, I Made Ady Wirawan, I Made Kerta Duana \\ Program Studi Kesehatan Masyarakat Fakultas Kedokteran Universitas Udayana \\ *Email: egiyagolda@gmail.com
}

\begin{abstract}
ABSTRAK
Kecelakaan lalu lintas merupakan masalah global dan banyak terjadi setiap harinya, sehingga perlu mengetahui kepatuhan pengendara khususnya pengendara kendaraan bermotor tentang keselamatan berkendara (safety riding) terkait pengetahuan safety riding. World Health Organization menyatakan kecelakaan lalu lintas merupakan penyebab utama kematian remaja di dunia pada rentang umur 15-29 tahun. Penelitian ini bertujuan untuk mengetahui gambaran kepatuhan remaja dengan kepatuhan safety riding di SMA Negeri di Kota Denpasar. Penelitian ini merupakan penelitian deskriptif kuantitatif dengan desain teknik cross-sectional. Sampel penelitian ini berjumlah 350 responden dengan menggunakan teknik pengambilan sampel secara multisage random sampling. Pengumpulan data dilakukan dengan cara wawancara menggunakan kuesioner dan studi dokumentasi kemudian data yang didapatkan diolah menggunakan software STATA. Hasil penelitian menunjukkan tingkat pengetahuan remaja terhadap kepatuhan safety riding termasuk dalam kategori tinggi, yaitu sebanyak 170 responden $(69,96 \%)$ dan sikap responden terhadap kepatuhan safety riding memiliki sikap yang positif yaitu sebesar 157 responden (70,40\%). Kepatuhan tentang safety riding termasuk dalam kategori patuh, yaitu sebanyak 241 responden $(68,86 \%)$. Berdasarkan hasil uji statistik didapatkan bahwa terdapat hubungan bermakna antara jenis kelamin dengan kepatuhan safety riding $(\mathrm{p}=0,03)$. Responden dengan jenis kelamin perempuan yaitu sebanyak 147 responden (73,50\%) lebih patuh terhadap safety riding daripada responden dengan jenis kelamin laki-laki. Perlu diadakannya sosialisasi dan edukasi mengenai safety riding oleh pihak sekolah dan juga pihak yang berwenang. Selain itu remaja perlu meningkatkan pengetahuan safety riding dan menumbuhkan perilaku safety riding melalui pembinaan disiplin berlalu lintas dan mencari informasi tentang safety riding di media massa dan internet.
\end{abstract}

Kata Kunci : Tingkat Pengetahuan, Safety Riding, Kepatuhan, Remaja

ABSTACT

Traffic accidents are a global problem and occur a lot every day, so the need to know the compliance of motorists, especially motorists about safety riding related to safety riding knowledge. The World Health Organization states that traffic accidents are the main cause of adolescent mortality in the world at the age range of 15-29 years. This study aims to determine the description of adolescent compliance with safety riding compliance in state high schools in Denpasar. This research is a quantitative descriptive study with cross-sectional design. The sample of this study was 350 respondents using a multisage random sampling technique. Data collection was carried out by interview using a questionnaire and study documentation and then the data obtained was processed using STATA software. The results showed the level of adolescent knowledge of safety riding compliance included in the high category, as many as 170 respondents (69.96\%) and the attitude of respondents towards safety riding compliance had a positive attitude of 157 respondents $(70.40 \%)$. Compliance about safety riding is included in the category of compliance, as many as 241 respondents $(68.86 \%)$. Based on the results of statistical tests found that there is a significant relationship between sex with safety riding compliance $(p=0.03)$. Respondents with female gender, namely 147 respondents $(73.50 \%)$ were more obedient to safety riding than respondents with male sex. Need to hold socialization and education about safety riding by the school and also the authorities. In addition, adolescents need to increase safety riding knowledge and foster safety riding behavior through fostering traffic discipline and finding information about safety riding in the mass media and the internet.

Keywords : Knowledge, Safety Riding, Compliance, Youth

\section{PENDAHULUAN}

Menurut World Health Organization sekitar 1,3 juta orang setiap tahunnya meninggal akibat kecelakaan lalu lintas, atau kurang lebih dari 3000 kematian setiap hari di seluruh dunia. WHO 
memperkirakan pada tahun 2020 kecelakaan lalu lintas merupakan penyebab terbesar ketiga kematian di seluruh dunia setelah penyakit jantung koroner dan tuberkolosis (TBC). Jumlah kecelakaan lalu lintas di Indonesia juga meningkat setiap tahunnya. Berdasarkan data Badan Pusat Statistik jumlah korban kecelakaan lalu lintas pada tahun 2007 adalah 49.553 jiwa dan meningkat pada tahun 2010 menjadi 66.488 jiwa, dengan korban meninggal sebanyak 19.873 jiwa, luka berat sebanyak 26.196 jiwa dan luka ringan sebanyak 63.809 jiwa (BPS, 2013). Bali merupakan salah satu provinsi dengan tingkat kecelakaan lalu lintas cukup tinggi. Menurut Direktorat Jenderal Perhubungan Darat, Provinsi Bali masuk dalam peringkat 9 jumlah kecelakaan terbanyak di Indonesia setelah Jawa dan Sumatera (Dirjen Perhub, 2013). Kejadian kecelakaan tertinggi di Bali terdapat di Kota Denpasar sebanyak 832 kejadian. Pada urutan kedua terjadi di wilayah Buleleng, dan selanjutnya di wilayah Gianyar (Polda Bali, 2011).

Beberapa faktor yang menjadi penyebab dari kecelakaan lalu lintas adalah faktor human (manusia), faktor kendaraan, faktor jalan (sarana prasarana) dan faktor cuaca dimana faktor manusia menjadi faktor tertinggi sebagai penyebab kecelakaan lalu lintas. Menurut penelitian disebutkan faktor manusia diantaranya adalah lengah, tidak tertib, tidak terampil, dan kecepatan tinggi (Ditjen PP dan PL, 2011). Pada penelitian tersebut juga disebutkan bahwa kecelakaan paling banyak terjadi pada anak muda usia 18-23 tahun yaitu sebanyak 259 dari 851 kecelakaan di sepanjang tahun 2008-2010. Hal ini dapat dikarenakan pada rentang umur 18-23 tahun merupakan kelompok umur yang memiliki mobilitas tinggi dengan berbagai aktifitas dan cenderung masih labil dalam berkendara karena usia yang muda (Chrussiawanti, 2015).

Berdasarkan Undang-Undang RI Nomor 22 tahun 2009 pasal 203 ayat 2, salah satu bentuk program nasional Keselamatan Lalu Lintas dan Angkutan Jalan adalah Cara Berkendara dengan Selamat (Safety Riding). Safety riding adalah perilaku mengemudi secara selamat yang dapat membantu menghindari terjadinya kecelakaan lalu lintas. Mencakup hal-hal yang berkaitan dengan tata cara berkendara yang aman, perlengkapan yang harus ada saat berkendara, dan kondisi kendaraan yang memungkinkan untuk digunakan. Dengan berperilaku mengutamakan keselamatan berkendara (safety riding) diharapkan dapat meningkatkan kesadaran pengendara terhadap segala kemungkinan yang terjadi selama berkendara baik itu keselamatan diri pengendara dan pengguna jalan lain.

Berdasarakan uraian tersebut, penulis tertarik melakulan penelitian untuk mengetahui kepatuhan terhadap perilaku keselamatan berkendara (safety riding) pada remaja SMA berdasarkan usia yang termasuk dalam kategori WHO sebagai usia penyebab kematiannya akibat kecelakaan lalu lintas. Saat ini belum diketahui bagaimana pengetahuan dan kepatuhan remaja berkendara sepeda motor terhadap safety riding di kota Denpasar. 


\section{METODE}

Penelitian ini merupakan penelitian merupakan penelitian deskriptif kuantitatif dengan desain teknik cross-sectional. Populasi pada penelitian ini adalah siswasiswi SMA Negeri $X$ di Kota Denpasar. Sampel penelitian ini berjumlah 350 responden dengan menggunakan teknik pengambilan sampel secara multisage random sampling. Data yang terkumpul kemudian diolah dengan menggunakan software STATA.

\section{HASIL DAN DISKUSI}

\section{Gambaran Lokasi Penelitian}

Penelitian ini dilakukan di SMA Negeri di Kota Denpasar. Pemilihan lokasi menggunakan cluster random sampling yang dilakukan dengan 2 tahapan yaitu pemilihan sekolah dan pemilihan kelas sebagai tempat penelitian.

$\underline{\text { Karakteristik Demografi Responden }}$

Tabel 1. Karakteristik Demografi Responden

\begin{tabular}{lcc}
\hline \multicolumn{1}{c}{ Variabel } & $\begin{array}{c}\text { Frekuensi } \\
\text { (f) }\end{array}$ & $\begin{array}{c}\text { Proporsi } \\
\text { (\%) }\end{array}$ \\
\hline Jenis Kelamin & & \\
$\quad$ Laki-laki & 150 & 42,86 \\
$\quad$ Perempuan & 200 & 57,14 \\
\hline Umur & & \\
14-16 Tahun & 189 & 54,00 \\
17-18 Tahun & 161 & 46,00 \\
\hline Masa & & \\
Berkendara & 228 & 65,14 \\
$\quad$ <3 Tahun & 122 & 34,86 \\
$\quad$ 3 Tahun & & \\
\hline
\end{tabular}

Siswa dan siswi SMA Negeri 6 Denpasar kelas $\mathrm{X}$ dan XI berada pada rentang usia 14 sampai 18 tahun dengan rata-rata umur $16 \quad(\mathrm{SD}=0,97)$ tahun. Responden terbanyak ada pada kelompok umur 14-16 tahun. Mayoritas siswa-siswi sudah mengendarai sepeda motor selama $<3$ tahun dengan rata-rata $3,02(\mathrm{SD}=1,42)$ tahun.

Gambaran Kepatuhan, Pengetahuan, dan Sikap Terhadap Safety Riding

Tabel 2. Gambaran Kepatuhan Safety Riding Responden

\begin{tabular}{lcc}
\hline Variabel & $\begin{array}{c}\text { Frekuensi } \\
(\mathbf{f})\end{array}$ & $\begin{array}{c}\text { Proporsi } \\
\mathbf{( \% )}\end{array}$ \\
\hline $\begin{array}{l}\text { Kepatuhan } \\
\text { Patuh }\end{array}$ & 241 & 68,86 \\
$\quad$ Tidak & 109 & 31,14 \\
Patuh & & \\
\hline Pengetahuan & & \\
$\quad$ Tinggi & 243 & 69,43 \\
$\quad$ Rendah & 107 & 30,57 \\
\hline Sikap & & \\
$\quad$ Positif & 223 & 63,71 \\
$\quad$ Negatif & 127 & 36,29 \\
\hline
\end{tabular}

Berdasarkan tabel diatas diketahui bahwa kepatuhan safety riding pada siswasiswi SMA Negeri 6 Denpasar termasuk dalam kategori patuh yaitu 68,86\%. Tingkat pengetahuan siswa-siswi tentang kepatuhan safety riding diketahui bahwa mayoritas responden memiliki tingkat pengetahuan yang tinggi yaitu sebesar 69,43\%. Sedangkan siswa-siswi SMA 6 Denpasar memiliki sikap yang positif terhadap kepatuhan safety riding yaitu sebesar $63,71 \%$. 
Distribusi Kepatuhan Safety Riding Responden

Berdasarkan Karakteristik Demografi

Tabel 3. Kepatuhan Safety Riding Berdasarkan Karakteristik Demografi Responden

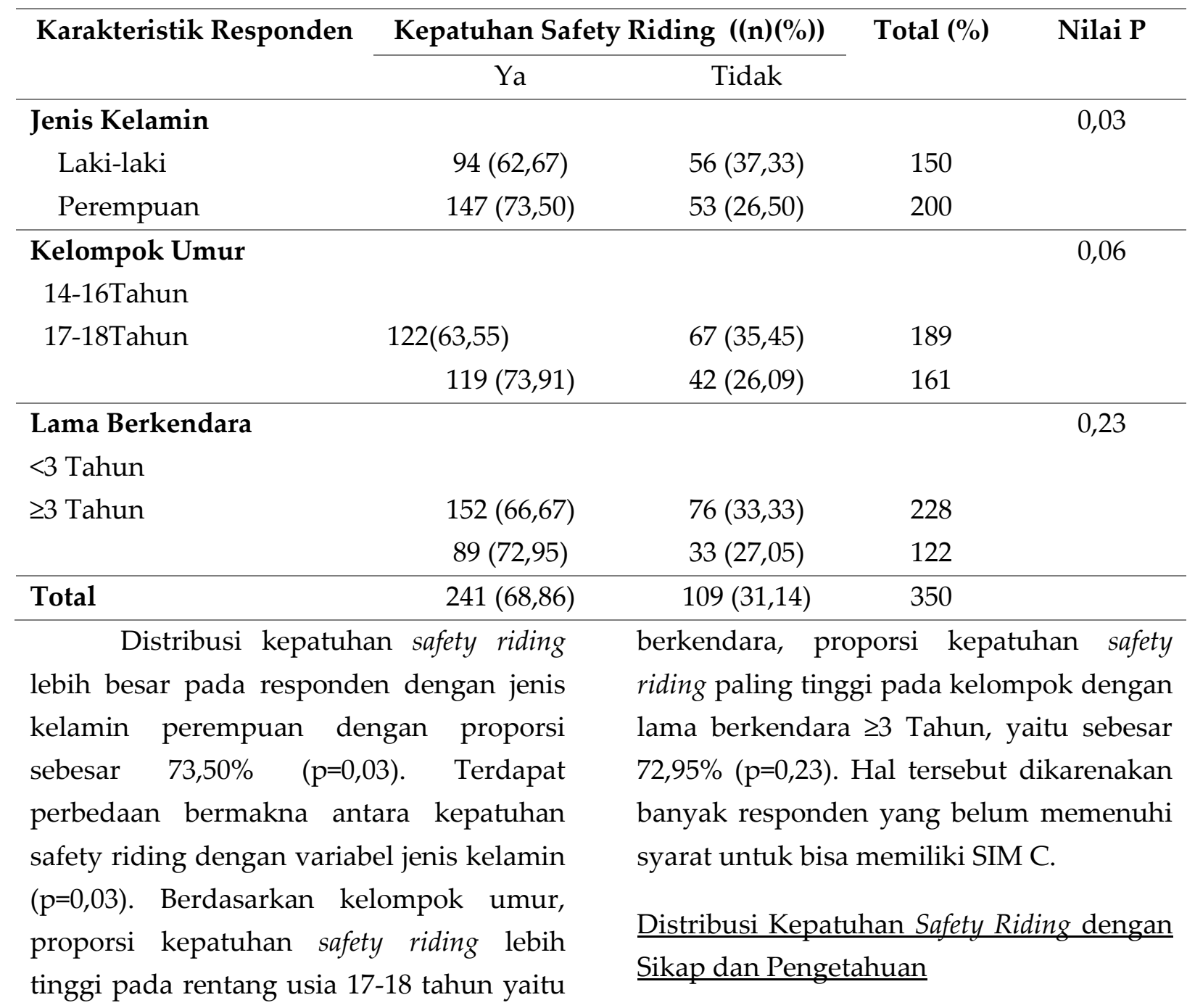
sebesar 73,91\% ( $p=0,06)$. Dilihat dari lama

Tabel 4. Kepatuhan Safety Riding dengan Sikap dan Pengetahuan

\begin{tabular}{|c|c|c|c|c|}
\hline \multirow[t]{2}{*}{ Variabel } & \multicolumn{2}{|c|}{ Kepatuhan Safety Riding ((n)(\%)) } & \multirow[t]{2}{*}{ Total (\%) } & \multirow[t]{2}{*}{ Nilai $\mathbf{P}$} \\
\hline & $\mathrm{Ya}$ & Tidak & & \\
\hline Sikap & & & & 0,40 \\
\hline Positif & $157(70,40)$ & $66(29,80)$ & $223(100)$ & \\
\hline Negatif & $84(66,14)$ & $43(33,86 \%)$ & $127(100)$ & \\
\hline Pengetahuan & & & & 0,50 \\
\hline Tinggi & $170(69,96)$ & $73(30,04)$ & $243(100)$ & \\
\hline Rendah & $71(66,36)$ & $36(33,64)$ & $107(100)$ & \\
\hline Total & $241(68,86)$ & $109(31,14)$ & $350(100)$ & \\
\hline $\begin{array}{lc} & \text { Berdasarkan } \\
\text { sikap } & \text { responden }\end{array}$ & $\begin{array}{l}5 \text { hasil analisis } \\
\text { p kepatuhan }\end{array}$ & $\begin{array}{l}\text { safety riding } \mathrm{n} \\
\text { dengan propor }\end{array}$ & $\begin{array}{l}\text { miliki sika } \\
70,40 \%(\mathrm{p}=\end{array}$ & $\begin{array}{l}\text { ang positif } \\
\text { ). Proporsi }\end{array}$ \\
\hline
\end{tabular}


kepatuhan safety riding responden termasuk kategori tinggi yaitu sebesar 69,96\% ( $p=0,50)$, dapat disimpulkan bahwa tidak terdapat hubungan yang spesifik antara tingkat pengetahuan siswa-siswi dengan kepatuhan safety riding. Hasil penelitian ini sejalan dengan penelitian yang dilakukan Utari (2010), dimana tidak terdapat hubungan yang bermakna antara pengetahuan mahasiswa Universitas Gunadarma dengan perilaku safety riding. Semakin tinggi tingkat pengetahuan responden, belum tentu semakin aman perilaku responden dalam berkendara sepeda motor (safety riding).

\section{SIMPULAN}

Berdasarkan hasil dan pembahasan, simpulan yang dapat diambil antara lain karakteristik demografi responden, sebagian besar remaja SMA Negeri 6 Denpasar berumur 14-16 tahun, berjenis kelamin perempuan, dengan masa berkendara $<3$ tahun. Gambaran kepatuhan pada remaja SMA Negeri 6 Denpasar, sebagian besar responden berperilaku patuh terhadap safety riding yaitu sebesar 68,86\%. Siswa-siswi SMA Negeri 6 Denpasar mayoritas memiliki tingkat pengetahuan yang tinggi yaitu sebesar $69,43 \%$ dan memiliki sikap yang positif terhadap kepatuhan safety riding yaitu sebesar 63,71\%. Kepatuhan safety riding lebih tinggi terjadi pada responden dengan jenis kelamin perempuan $(\mathrm{p}=0,03)$. Sedangkan variabel lain kelompok umur $(0,06)$ dan lama berkendara $(p=0,23)$ tidak menunjukkan perbedaan yang bermakna dengan kepatuhan safety riding. Tidak terdapat hubungan yang bermakna antara pengetahuan dengan kepatuhan safety riding $(\mathrm{p}=0,50)$. Tidak terdapat hubungan yang bermakna antara sikap dengan kepatuhan safety riding $(\mathrm{p}=0,40)$.

\section{DAFTAR PUSTAKA}

Aeni, Q., 2016. Faktor yang Berhubungan dengan Perilaku Safety Riding pada Mahasiswa Kesehatan Masyarakat Sebagai Pengendara Sepeda Motor. Surakarta. Jurusan Kesehatan Masyarakat Fakultas Ilmu Kesehatan Universitas Muhammadiyah Surakarta.

Badan Pusat Statistik, 2013. Indonesia dalam Angka 2012. Jakarta: BPS.

Badan Pusat Statistik Provinsi Bali, 2015. Denpasar Dalam Angka 2015. Available:

https://denpasarkota.bps.go.id/

Chrussiawanti, N., 2015. Hubungan Tingkat Pengetahuan dengan Kepatuhan Safety Riding Pada Remaja di SMA Negeri 2 Sukoharjo. Surakarta: Progam Studi S-1 Keperawatan Sekolah Tinggi Ilmu Kesehatan Kusuma Husada Surakarta.

Direktoral Jenderal Perhubungan Darat, 2015. Perhubungan Darat Dalam Angka 2014. Available:

http://hubdat.dephub.go.id/data-ainformasi/pdda/tahun-2015/1765perhubungan-darat-dalamangka-edisi-april-2015/download 
Vol. 5 No. $1: 51$ - 56

Ditjen PP dan PL. 2011. Modul Penemuan dan Tata laksana Korban Akibat Kecelakaan Lalu Lintas Jalan.

Khakim, R., 2016. Hubungan Antara Umur, Tingkat Pendidikan, Masa Berkendara, Dan Pengetahuan Dengan Perilaku Safety Riding. Universitas Muhammadiyah Semarang

Satuan Lalu Lintas Kepolisian Resor Kota Denpasar, 2011. Laporan Kejadian Kecelakaan Lakalantas. Unit Laka. Denpasar, Bali.

Utari, G. C., 2010, Hubungan Pengetahuan, Sikap, Persepsi Dan Keterampilan Mengendara Mahasiswa Terhadap Perilku Keselamatan Berkendara (Safety Riding) di Universitas Gunadarma Bekasi. Jakarta:
Fakultas Kedokteran dan Ilmu Kesehatan Universitas Islam Negeri Syarif Hidayatullah.

WHO Despite Progress, 2015. Road Traffic Deaths Remain Too High. Geneva, Switzerland: World Health Organization. 